\title{
TO THE 85TH BIRTHDAY OF VASILII SERGEEVICH VLADIMIROV
}

\author{
This issue of Theoretical and Mathematical Physics \\ is dedicated to the 85th birthday of
}

\section{Vasilii Sergeevich Vladimirov}

Vasilii Sergeevich Vladimirov is an outstanding scientist and has contributed fundamentally to the development of modern mathematical physics. We are especially honored because Vladimirov is one the founders of Theoretical and Mathematical Physics. From the establishment of the journal in 1969 until 1989, he was the Deputy Chief Editor and actually in charge of the journal.

The scientific interests of Vladimirov embrace a large scope of problems in mathematics and theoretical physics. In developing this issue, dedicated to Vladimirov's birthday, we decided to include

works by his most closely associated students and colleagues even if the works go somewhat beyond the traditional profile of our journal.

We wish Vladimir Sergeevich strong health and many years of productive work for the benefit of science.

Translated from Teoreticheskaya i Matematicheskaya Fizika, Vol. 157, No. 3, pp. 323-324, December, 2008. 